\title{
Analysis of Promoter Hypermethylation of Death- Associated Protein Kinase and $p 16$ Tumor Suppressor Genes in Actinic Keratoses and Squamous Cell Carcinomas of the Skin
}

Lisa N. Tyler, M.D., Lingbao Ai, M.D., Chunlai Zuo, M.D., Chun-Yang Fan, M.D., Ph.D., Bruce R. Smoller, M.D.

Deparents of Pathology (LNT, LA, CL, CYF, BRS) and Dermatology (BRS), University of Arkansas for Medical Sciences; and John L. McClellan Memorial Veterans Administration Hospital (CYF, BRS), Little Rock, Arkansas

Death-associated protein kinase is a serine/threonine protein kinase implicated in promoting apoptosis and tumor suppression, whereas p16 is a tumor suppressor gene that inhibits cyclin-dependent kinase 4 and 6 activity and arrests the cell cycle in the G1 phase. Hypermethylation of deathassociated protein kinase or $p 16$ gene with resultant gene inactivation has been described in a wide variety of human cancers. Promoter methylation of the death-associated protein kinase and $p 16$ gene has been found in about $55 \%$ and $30 \%$ cases of head and neck squamous cell carcinoma respectively but has not yet been analyzed in cutaneous premalignant and malignant lesions. A total of 33 cases were examined for evidence of death-associated protein kinase and $p 16$ hypermethylation and these consist of 9 cases of spongiotic dermatitis as nonneoplastic skin control, 9 cases of actinic keratosis, 8 cases of squamous cell carcinoma in situ, and 7 cases of invasive squamous cell carcinoma. Deathassociated protein kinase promoter methylation was detected in 1 case of squamous cell carcinoma in situ and 1 case of nonneoplastic skin control but none of the cases of invasive squamous cell carcinoma or actinic keratosis. P16 promoter methylation was detected in 1 case of invasive squamous cell carcinoma and 1 case of nonneoplastic skin control but none of the cases of squamous cell carcinoma in situ or actinic keratosis. Promoter hyper-

\footnotetext{
Copyright $\odot 2003$ by The United States and Canadian Academy of Pathology, Inc.

VOL. 16, NO. 7, P. 660, 2003 Printed in the U.S.A

Date of acceptance: May 1, 2003.

Presented at the 92nd Annual Meeting of the United States and Canadian Academy of Pathology, Washington, D.C., March 22-28, 2003.

Address reprint requests to: Bruce R. Smoller, M.D., Deparent of Pathology, University of Arkansas for Medical Sciences, 4301 West Markham, Slot 517, Little Rock, AR 72205; fax: 501-603-1479; e-mail: smollerbruce@exchange.uams.edu.

DOI: 10.1097/01.MP.0000077516.90063.7D
}

methylation of the death-associated protein kinase and $p 16$ genes does not appear to play an important role in the development of cutaneous squamous cell carcinoma. The data thus suggest that the mechanisms of ultraviolet-induced cutaneous carcinomas differ from those involved in the development of head and neck squamous cell carcinoma, a malignant disease induced by tobacco and alcohol exposure.

KEY WORDS: Cutaneous squamous cell carcinoma, Death-associated protein kinase, p16 tumor suppressor gene, Promoter hypermethylation.

Mod Pathol 2003;16(7):660-664

Control of gene expression is a complex process that is involved in the development of many cancers. Death-associated protein kinase is a multidomain calmodulin regulated serine/threonine protein kinase implicated in control of apoptosis, tumor suppression and susceptibility to disease (1). Death-associated protein kinase is involved in apoptosis induced by Fas ligand, TNF- $\alpha$, and detachment-induced cell death. Death-associated protein kinase was recently characterized as an upstream regulator of $p 53(2,3)$. Inactivation of the deathassociated protein kinase promoter contributes to immortalization of cells and development of cancer.

The tumor suppressor function of $p 16$ is due to its inhibition of the catalytic activity of the cyclindependent kinase 4-6/cyclin D complex that is required for phosphorylation of retinoblastoma protein $(p R b)(4,5)$. The unphosphorylated $p R b$ is specifically bound to the E2F family of transcription factors, thus inhibiting their activities, essential for cell cycle progression $(6,7)$. The $p R b / \mathrm{E} 2 \mathrm{~F}$ complex releases E2F transcriptional factors upon phosphorylation of $\mathrm{pRb}$ by cyclin-dependent kinase 
4-6/cyclin D complex and promotes cell cycle progression past the $G_{1}$ checkpoint (6-8). By binding to cyclin-dependent kinase $4 / 6$ and inhibiting $p R b$ phosphorylation, $p 16$ promotes the formation of $p R b / \mathrm{E} 2 \mathrm{~F}$ repressive complex and cell cycle arrest (8).

Gene inactivation can occur via a number of mechanisms, including homozygous deletion, point mutation in the coding sequence, and $\mathrm{CpG}$ hypermethylation in the promoter region. Promoter hypermethylation of death-associated protein kinase has been reported in B-cell lymphomas and multiple myeloma (9), urinary bladder carcinoma (10), gastric carcinoma (11), prostate cancer (12), non-small cell carcinoma of the lung (13), head and neck squamous cell carcinoma $(14,15)$, and nasopharyngeal carcinoma (3).

Hypermethylation of $p 16$ promoter has also been identified in head and neck squamous cell carcinoma (14-16), lung cancer (13), colorectal cancer (17), B-cell lymphoma (18), glioblastoma multiforme (19), and gastric carcinoma $(20,21)$.

Recent work in our laboratory identified increased p16 expression in actinic keratosis, squamous cell carcinoma in situ, and invasive squamous cell carcinoma of the skin using immunohistochemistry (22). Promoter hypermethylation of death-associated protein kinase and $p 16$ in cutaneous malignant lesions has not been analyzed previously.

\section{MATERIALS AND METHODS}

\section{Tissue Collection}

A total of 33 cases of nonneoplastic skin, actinic keratosis, and skin cancers were gathered from the paraffin block archives in the Deparent of Pathology, University of Arkansas for Medical Sciences, Little Rock, in 2002. These cases consisted of 8 cases of nonneoplastic skin, 9 cases of actinic keratosis, 8 cases of squamous cell carcinoma in situ, and 7 cases of invasive squamous cell carcinoma (Table 1). The histology of each case was reviewed, and representative tissue sections containing the pertinent epithelial component were selected for extraction of DNA for promoter methylation analysis.

\section{Sample Collection and DNA Extraction}

DNA samples were collected using the EX-WAX DNA Extraction Kit (Intergen Co., New York, NY) from five deparaffinized 5- $\mu \mathrm{m}$-thick tissue sections from each tissue block. Human placental DNA (Sigma) was used as a negative control, and CpGenome universal methylated human DNA (Intergen) served as a positive control.
TABLE 1. Death Associated Protein Kinase and $p 16$ Promoter Hypermethylation in Skin Lesions

\begin{tabular}{|c|c|c|c|}
\hline Sample\# & Diagnosis & DAPK* MSP $^{*}$ & p16 MSP \\
\hline 4 & Nonneoplastic Skin & $-\dagger$ & - \\
\hline 14 & Nonneoplastic Skin & - & - \\
\hline 6 & Nonneoplastic Skin & - & - \\
\hline 25 & Nonneoplastic Skin & - & - \\
\hline 8 & Nonneoplastic Skin & - & - \\
\hline 29 & Nonneoplastic Skin & $+\ddagger$ & - \\
\hline 16 & Nonneoplastic Skin & - & - \\
\hline 3 & Nonneoplastic Skin & - & + \\
\hline 30 & Nonneoplastic Skin & - & - \\
\hline 15 & Actinic Keratosis & - & - \\
\hline 7 & Actinic Keratosis & - & - \\
\hline 28 & Actinic Keratosis & - & - \\
\hline 26 & Actinic Keratosis & - & - \\
\hline 22 & Actinic Keratosis & - & - \\
\hline 33 & Actinic Keratosis & - & - \\
\hline 32 & Actinic Keratosis & - & - \\
\hline 18 & Actinic Keratosis & - & - \\
\hline 11 & Actinic Keratosis & - & - \\
\hline 10 & SCC $\$$ in situ & - & - \\
\hline 35 & SCC in situ & - & - \\
\hline 24 & SCC in situ & - & - \\
\hline 34 & SCC in situ & - & - \\
\hline 13 & SCC in situ & + & - \\
\hline 19 & SCC in situ & - & - \\
\hline 36 & SCC in situ & - & - \\
\hline 12 & SCC in situ & - & - \\
\hline 2 & Invasive SCC & - & - \\
\hline 9 & Invasive SCC & - & - \\
\hline 5 & Invasive SCC & - & - \\
\hline 1 & Invasive SCC & - & + \\
\hline 21 & Invasive SCC & - & - \\
\hline 17 & Invasive SCC & - & - \\
\hline 31 & Invasive SCC & - & - \\
\hline
\end{tabular}

* DAPK; death associated protein kinase.

- MSP; methylation-specific PCR.

$\dagger-$; negative MSP or negative for promoter hypermethylation.

$\ddagger+$; positive MSP or positive for promoter hypermethylation.

$\S$ SCC; squamous cell carcinoma.

\section{Bisulfite modification of DNA for methylation- specific PCR}

In DNA samples from cutaneous lesions, negative and positive controls were subjected to bisulfite modification before methylation-specific PCR using CpGenome DNA modification Kit (Intergen).

\section{PCR amplification and primers}

Amplification of the promoter region of the $p 16$ and death-associated protein kinase genes was carried out in a Touchgene Gradient Thermal Cycler (Techne Inc., Princeton, NJ) in a 50- $\mu$ L PCR reaction mixture containing $2 \mu \mathrm{L}$ of bisulfite-treated genomic DNA, dNTPs (each at $200 \mu \mathrm{M}$ ), primers (50 pmol each per reaction), $2.5 \mathrm{mM} \mathrm{MgCl}_{2}$, and $1.25 \mathrm{U}$ Hotstar Taq (Qiagen, Valencia, CA) in $1 \times$ PCR buffer. All reagents were supplied with the Qiagen Hotstar Taq Kit (Qiagen). The only exception was the dNTP mix (Roche Molecular Biochemicals, Indianapolis, IN).

The primers used for the unmethylated reaction were as follows: for $p 16$ gene are designed as follows: 5'-TTA TTA GAG GGT GGG GTG GAT TGT-3' (sense); and 5'-CAA CCC CAA ACC ACA ACC ATA-3' 
(antisense); for death-associated protein kinase, 5'GGA GGA TAG TTG GAT TGA GTT AAT GTT-3' (sense) and 5'-CAA ATC CCT CCC AAA CAC CAA-3' (antisense). The primers used for the methylated reaction were as follows: for $p 16,5$ '-TTA TTA GAG GGT GGG GCG GAT CGC-3' (sense) and 5'-GAC CCC CGA ACC GCG ACC GTA A-3'(antisense); for death-associated protein kinase, 5'-GGA TAG TCG GAT CGA GTT AAC GTC-3' (sense) and 5'-CCC TCC CAA ACG CGC A-3' (antisense), as described previously (14). All primers were purchased from Operon Technologies Inc. (Alameda, CA). The PCR conditions were as follows: initial denaturation and hot start at $95^{\circ} \mathrm{C}$ for 15 minutes, then 40 cycles consisting of 30 seconds at $95^{\circ} \mathrm{C}, 30$ seconds at $60^{\circ} \mathrm{C}$ (unmethylated reactions) or $65^{\circ} \mathrm{C}$ (methylated reactions), and 1 minute at $72^{\circ} \mathrm{C}$. Positive and negative control DNA samples and controls without DNA were used for each set of PCR reactions.

\section{RESULTS}

We used a highly specific and sensitive methylation-specific PCR to analyze the status of promoter methylation of $p 16$ and death-associated protein kinase genes in 33 cases of nonneoplastic skin, actinic keratosis, carcinoma in situ, and invasive carcinomas using gene specific primer sets as described previously (14). The distribution of cases and analysis results are presented in Table 1. Spongiotic dermatitis was used as a nonneoplastic skin control. Briefly, death-associated protein kinase promoter hypermethylation was detected only in one of eight cases of squamous cell carcinoma in situ and one of eight cases of nonneoplastic skin. None of the cases of invasive squamous cell carcinoma or actinic keratosis displayed deathassociated protein kinase promoter hypermethylation. The $p 16$ promoter hypermethylation was detected only in one of seven cases of invasive squamous cell carcinoma and one of eight cases of nonneoplastic skin. None of the cases of squamous cell carcinoma in situ or actinic keratosis showed p16 promoter hypermethylation. Figure 1 shows representative methylation-specific PCR data obtained from five skin samples. Samples 13 (squa-

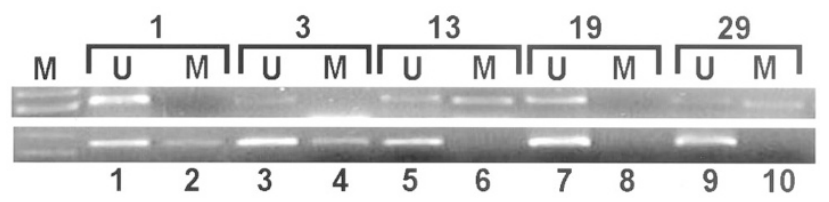

FIGURE 1. Bisulfite-modified DNA harvested from skin samples designated 1 (Lanes 1 and 2), 3 (Lanes 3 and 4), 13 (Lanes 5 and 6), 19 (Lanes 7 and 8), and 29 (Lanes 9 and 10) was subjected to methylationspecific PCR using unmethylated (U) or methylated-specific (M) MSP primer sets for death-associated protein kinase (upper panel) and p16 (lower panel) promoters. mous cell carcinoma in situ) and 29 (nonneoplastic skin) show amplification of both unmethylated and methylated-specific amplicons for death-associated protein kinase, indicating the presence of deathassociated protein kinase promoter hypermethylation (Cases 13 and 29 in Fig. 1; upper panel). In Samples 1 (invasive squamous cell carcinoma), 3 (nonneoplastic skin), and 19 (squamous cell carcinoma in situ), only the amplification of unmethylated-specific amplicons is seen, indicative of a lack of death-associated protein kinase promoter hypermethylation in these samples (Cases 1, 3, and 19 in Fig. 1; upper panel). In Samples 1 (invasive squamous cell carcinoma) and 3 (nonneoplastic skin), we observed amplification with both unmethylated and methylated-specific amplicons for $p 16$ gene, indicating the presence of $p 16$ promoter hypermethylation in both samples (Cases 1 and 3 in Fig. 1; lower panel). Samples 13 (squamous cell carcinoma in situ), 19 (squamous cell carcinoma in situ), and 29 (nonneoplastic skin) show amplification with p16 unmethylated-specific primers only, indicating a lack of p16 promoter hypermethylation in these samples (Cases 13, 19, and 29 in Fig. 1; lower panel). Positive and negative controls worked appropriately in each round of PCR reaction.

\section{DISCUSSION}

Gene expression is controlled by a number of mechanisms including genetic factors, such as gene deletion, point mutation, and epigenetic factors such as promoter hypermethylation. Promoter hypermethylation is perhaps one of the most common molecular changes in human cancer $(23,24)$. DNA methylation typically occurs at cytosines located 5' to a guanosine (CpG) (25). The number of CpG nucleotides is markedly decreased to about $20 \%$ of the predicted frequency in the mammalian genome except for the $\mathrm{CpG}$ islands where $\mathrm{CpG}$ nucleotides occur in the expected frequency. These islands are 500 to 2000 base-pairs in length and located most frequently around or within the transcription start sites of about half of human genes (25). Although $\mathrm{CpG}$ islands are unmethylated in normal tissues, they are methylated to varying degrees in many human cancer types $(23,26)$. These epigenetic silencing often cooperates with genetic changes (gene mutation and deletion) in silencing a number of tumor suppressor genes such as p16 ${ }^{\text {Ink4a }}$, E-cadherin, $p V H L$, death-associated protein kinase, and MLH1 (27). Promoter hypermethylation of one allele is frequently accompanied by deletion of the opposite allele $(28,29)$, simulating the type of loss of heterozygosity usually seen with loss of tumor suppressor function due to genetic alterations (e.g., point mutation). 
Because both $p 16$ and death-associated protein kinase have been established as targets for epigenetic alterations in multiple tumor types, we attempted to determine the prevalence of $p 16$ and death-associated protein kinase promoter hypermethylation in the continuum from nonneoplastic skin to actinic keratosis, squamous cell carcinoma in situ, and invasive squamous cell carcinoma. In this study, we found that the frequency of p16 and death-associated protein kinase promoter hypermethylation was very low ( $6 \%$ for both genes) in nonneoplastic and malignant skin lesions, indicating that the $p 16$ and death-associated protein kinase genes are not the targets for epigenetic silencing in cutaneous squamous carcinogenesis.

There is no apparent consensus regarding the roles of p16 tumor suppressor gene in ultravioletinduced cutaneous squamous carcinogenesis. Although Mortier et al. (30) reported increased loss of heterozygosity and loss of protein expression of the p16 gene during progression of actinic keratosis to invasive squamous cell carcinoma, we found that p16 gene expression is greatly induced from actinic keratosis to invasive squamous cell carcinoma (22). Our results are consistent with those obtained by others who showed that ultraviolet-irradiation to skin keratinocytes could induce $p 16$ expression (3134 ) as an adaptive response, causing G2 phase cell cycle arrest (33). Alternatively, high levels of $p 16$ protein in invasive squamous cell carcinoma in our previous study may result from overexpression of mutant $p 16$ protein (analogous to that described with mutant $p 53$ ).

Although epigenetic alterations and gene expression of the death-associated protein kinase gene have been well studied in many different human tumors, similar studies on cutaneous squamous cell carcinoma are not found in the English literature. Thus, the roles of this gene in ultraviolet-induced skin cancer remain largely unknown.

Promoter hypermethylation of $p 16$ and deathassociated protein kinase genes, by contrast, has been characterized in head and neck squamous cell carcinoma, an etiologically distinct (tobaccoinduced) but morphologically similar disease. The prevalence of promoter hypermethylation is estimated at about $30 \%$ for $p 16$ (27) and 55\% for deathassociated protein kinase $(3,14)$ in head and neck squamous cell carcinoma. The p16 protein expression analyzed by immunohistochemical staining is frequently lost in head and neck squamous cell carcinoma, ranging from $55 \%$ to $90 \%$ in three studies involving 332 cases with an average frequency of $74 \%$ (35-37). Thus, low prevalence of p16 and death-associated protein kinase promoter hypermethylation in this study and frequent expression of p16 protein in our previous study (22) on skin lesions suggest that the mechanisms of ultraviolet- induced cutaneous squamous carcinomas differ from those involved in the development of head and neck squamous cell carcinoma, a neoplasm induced by exposure to tobacco and alcohol.

In summary, we have used a highly specific and sensitive methylation-specific PCR to determine the prevalence of promoter hypermethylation in two well-known tumor-causing genes, p16 and death-associated protein kinase. Death-associated protein kinase and $p 16$ hypermethylation does not appear to be involved in the development of ultraviolet-induced cutaneous squamous carcinomas. These findings indicate that the mechanisms for the development of malignancy differ for cutaneous squamous cell carcinoma from those arising in the head and neck region.

\section{REFERENCES}

1. Velentza AV, Schumacher AM, Weiss C, et al. A protein kinase associated with apoptosis and tumor suppression. J Biol Chem 2001;276:38956-65.

2. Kogel D, Prehn JHM, Scheidann KH. The DAP kinase family of pro-apoptotic proteins: novel players in the apoptotic game. Bioessays 2001;23:352-8.

3. Wong TS, Chang HW, Tang KC, et al. High frequency of promoter hypermethylation of the death-associated protein kinase gene in nasopharyngeal carcinoma and its detection in the peripheral blood in patients. Clin Cancer Res 2002;8: 433-7.

4. Serrano M, Hannon GJ, Beach D. A new regulatory motif in cell-cycle control causing specific inhibition of cyclin D/CDK4. Nature 1993;366:704-7.

5. Serrano M, Lee H, Chin L, et al. Role of the INK4a locus in tumor suppression and cell mortality. Cell 1996;85:27-37.

6. Hengstschlager M, Hengstschlager-Ottnad E, Pusch O, et al. The role of p16 in the E2F-dependent thymidine kinase regulation. Oncogene 1996;12:1635-43.

7. Lukas J, Petersen BO, Holm K, et al. Deregulated expression of E2F family members induces S-phase entry and overcomes p16-mediated growth suppression. Mol Cell Biol 1996;16:1047-57.

8. Rocco JW, Sidransky D. p16 (MTS-1/CDKN2/INK4a) in cancer progression. Exp Cell Res 2001;264:42-55.

9. $\mathrm{Ng} \mathrm{MH}$, To KW, Lo KW, et al. Frequent death-associated protein kinase promoter hypermethylation in multiple myeloma. Clin Cancer Res 2001;7:1724-9.

10. Tada Y, Wada M, Taguchi K, et al. The association of deathassociated protein kinase hypermethylation with early recurrence in superficial bladder cancers. Cancer Res 2002;62: 4048-53.

11. Lee TL, Leung WK, Chan MWY, et al. Detection of gene promoter hypermethylation in the tumor and serum of patients with gastric carcinoma. Clin Cancer Res 2002;8:1761-6.

12. Maruyama R, Toyooka S, Toyooka KO, et al. Aberrant promoter methylation profile of prostate cancers and its relationship to clinicopathological features. Clin Cancer Res 2002;514-9.

13. Zochbauer-Muller S, Fong KM, Virmani AK, et al. Aberrant promoter methylation of multiple genes in non-small cell lung cancers. Cancer Res 2001;61:249-55.

14. Rosas SLB, Koch W, Carvalho MDC, et al. Promoter hypermethylation patterns of p16, 06-methylguanine-DNA methyltransferase, and death-associated protein kinase in tumors 
and saliva of head and neck cancer patients. Cancer Res 2001;61:939-42.

15. Sanchez-Cespedes M, Esteller M, Wu L, et al. Gene promoter hypermethylation in tumors and serum of head and neck cancer patients. Cancer Res 2000;60:892-5.

16. El-Naggar AK, Lai S, Clayman G, et al. Methylation, a major mechanism of p16/CDKN2 gene inactivation in head and neck squamous carcinoma. Am J Pathol 1997;151:1767-74.

17. Liang JT, Chang KJ, Chen JC, et al. Hypermethylation of the p16 gene in sporadic T3N0M0 stage colorectal cancers: association with DNA replication error and shorter survival. Oncology 1999;57:149-56.

18. Child FJ, Scarisbrick JJ, Calnje E, et al. Inactivation of tumor suppressor genes p15(INK4b) and p16(INK4a) in primary cutaneous B cell lymphoma. J Invest Dermatol 2002;118: 941-8.

19. Park SH, Jung KC, Ro JY, et al. 5' CpG island methylation of p16 is associated with absence of p16 expression in glioblastomas. J Korean Med Sci 2000;15:555-9.

20. Shim YH, Kang GH, Ro JY. Correlation of p16 hypermethylation with p16 protein loss in sporadic gastric carcinomas. Lab Invest 2000;80:689-95.

21. Vo QN, Geradts J, Gulley ML, et al. Epstein-Barr virus in gastric adenocarcinomas: association with ethnicity and CDKN2A promoter methylation. J Clin Pathol 2002;55:66975 .

22. Hodges A, Smoller BR. Immunohistochemical comparison of p16 expression in actinic keratoses and squamous cell carcinomas of the skin. Mod Pathol 2002;15:1121-5.

23. Jones PA. DNA methylation errors and cancer. Cancer Res 1996;56:2463-7.

24. Baylin SB, Herman JG. DNA methylation in tumorigenesis: epigenetics joins genetics. Trends Genet 2000;16:1068-70.

25. Widschwendter M, Jones PA. The potential prognostic, predictive, and therapeutic values of DNA methylation in cancer. Clin Cancer Res 2002;8:17-21.

26. Jones PA, Laird PW. Cancer epigenetics come of age. Nat Genet 1999;15:163-7.
27. Herman JG, Baylin SB. Promoter-region hypermethylation and gene silencing in human cancer. In: Vogt PA, JaPK, editors. DNA methylation and cancer. 1st ed. New York: Springer-Verlag; 2000. p. 35-50.

28. Merlo A, Herman JG, Mao L, et al. 5'-CpG island methylation is associated with transcriptional silencing of the tumor suppressor p16/CDKN2/MTS1 in human cancers. Nat Med 1995;1:686-92.

29. Herman JG, Latif F, Weng Y, et al. Silencing of the VHL tumor-suppressor gene by DNA methylation in renal carcinoma. Proc Natl Acad Sci U S A 1994;91:9700-4.

30. Mortier L, Marchetti P, Delaporte E, et al. Progression of actinic keratosis to squamous cell carcinoma of the skin correlates with deletion of the $9 \mathrm{p} 21$ region encoding the p16(INK4a) tumor suppressor. Cancer Lett 2002;176:205-14.

31. Pavey S, Conroy S, Russell T, et al. Ultraviolet radiation induces p16CDKN2A expression in human skin. Cancer Res 1999;59:4185-9.

32. Ahmed NU, Ueda M, Ichihashi M. Induced expression of p16 and p21 proteins in UVB-irradiated human epidermis and cultured keratinocytes. J Dermatol Sci 1999;19:175-81.

33. Pavey S, Russell T, Gabrielli B. G2 phase cell cycle arrest in human skin following UV irradiation. Oncogene 2001;20: 6103-10.

34. Chazal M, Marionnet C, Michel L, et al. P16(INK4A) is implicated in both the immediate and adaptative response of human keratinocytes to UVB irradiation. Oncogene 2002;21: 2652-61.

35. Reed AL, Califano J, Cairns P, et al. High frequency of p16 (CDKN2/MTS-1/INK4A) inactivation in head and neck squamous cell carcinoma. Cancer Res 1996;56:3630-3.

36. Gruttgen A, Reichenzeller M, Junger M, et al. Detailed gene expression analysis but not microsatellite marker analysis of 9p21 reveals differential defects in the INK4a gene locus in the majority of head and neck cancers. J Pathol 2001;194: 311-7.

37. Bova RJ, Quinn DI, Nankervis JS, et al. Cyclin D1 and p16INK4a expression predict reduced survival in carcinoma of the anterior tongue. Clin Cancer Res 1999;5:2810-9. 